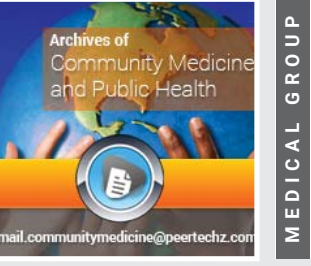

\title{
Medical and scientific research in Libya. Position on sustained developmental goals
}

\author{
Aisha Nasef* \\ Scientific Council of Laboratory Medicine, Medical Specialty Council, Libya
}

Received: 06 December, 2021

Accepted: 03 January, 2022

Published: 04 January, 2022

*Corresponding author: Aisha Nasef, Scientific Council of Laboratory Medicine, Medical Specialty Council, Libya, Tel: +218910419561; E-mail: Nasef@Doctor.com

Keywords: Science Engineering Technology and Innovation (SETI); Research; Libya; SDG

Copyright License: (c) 2022 Nasef A. This is an openaccess article distributed under the terms of the Creative Commons Attribution License, which permits unrestricted use, distribution, and reproduction in any medium, provided the original author and source are credited.

https://www.peertechzpublications.com

\section{Check for updates}

\section{Abstract}

UNESCO recommendation on science and scientific researchers aims to support scientific research and science as tools for achievements of the 17 sustainable development goals (SDGs). Countries are responded differently to these recommendations. In this article we tried to assess the polices and measures taken by Libya State as a developing country to meet these recommendations. The assessment reveals big shortcomings in the Libyan government's response to UNESCO recommendation on science and scientific researchers.

\section{Introduction}

Libyan doctors start to provide good medical services about Sixty years back. However, they could not produce sound research, as policymakers in health sector ignore its importance and did not support scientific research.

Absence of research results in progressive decline of health services and lack of evidence-based decision making and resulted in negative impact on good health which represent the Third goal among 17 sustainable developmental goal (SDGs).

This situation is applicable for all scientific sectors. Currently, Libya is at the back of the world in terms research, health services, education, technology, engineering, science, and innovation with lack of sustainability elements for all sustainable goals.

Scientific and technological developments benefit all society. United nation Member States recognize the value of science, research and, technology for tackling various global problems. However, research and new technology carry a certain risk. To assume responsibility towards humankind and the environment, it's essential to achieve the 17 goals of sustained developmental goals (SDGs).
UNESCO recommendation on science and scientific researchers, was adopted by a consensus and focus on 10 key areas [1]. The report on the implementation of the recommendation on science and scientific researchers was on 2017. The first national report on the implementation of the recommendation should be delivered by 31 March 2021.

National reports are essentials before decision on new standards on open science and the ethics of artificial intelligence. Libya needs to reconsider the importance of research seriously and support development of science and scientific research to improve people health and to achieve the SDGs.

In this review, an assessment of the response and or readiness of the Libyan state to the recommendation of UNESCO in science and for scientific researchers was conducted.

The assessment presents interviews, published and unpublished studies for mapping of existing Libyan research eco-system; infra-structure, resources, fundings, the laws, policies, regulation, research culture, and the operational tools as specified by UNESCO, and their appropriacies for contribution to the SDGs.

\section{Libyan research centers (Etat de Lieu)}

Libya state does not have a national documentation and 
reporting system according to the standards. It's more likely to be data rather than knowledge that we can use them for assessment and evidence-based decision making!

Considering the infrastructure for research, Libya has 24 designated research centers belonging to the Ministry of Higher Education and Scientific Research. As an example, Libya has a Solar energy research center, Medical, Biomedical technology, Remote sensing, and Space Sciences, Electronic systems, Software and Aviation, Engineering and information technology, Desert research and development of desert societies, Libyan Olive Tree, Palm tree, Terrestrial and marine environment research, Higher Technical Center for Training and Production, Advanced Technology Center, Economic research (two centers). Libyan High Professional Plumbing Center, Advanced Center for chemical analyzes research centers.

All these have financial and administrative independence. Most of the expenses are allocated for salaries and conduction budgets. Expenditure includes renting/ properties, operational costs, privileges for the employers and executives. qualified active researchers are presenting from $25-50 \%$ of workers in these centers and even below! [2-4].

In the following paragraphs, an evaluation of 10 key areas as recommended by UNESCO will be performed [1]

UNESCO First key area is the responsibility of science towards human dignity, progress, justice, peace, welfare of humankind, just and inclusive societies and respect for the environment. Looking at available research centers, we can figure that objective is not clear or was not set as all. Research is not promoted in all areas of society in Libya. Social research is not included, which reflects considering social research as not scientific and primordial for society and economic development!

\section{Research culture in Libya}

Second key area is the acknowledgment of the need for science to meaningfully interact with society and vice versa, where Society is engaged in science and research through the identification of knowledge needs, the conduct of scientific research, and the use of results.

Libya does not endeavor to ensure that Research And Development (R\&D) is undertaken and being responsive to Libya's needs and contributing to the alleviation of urgent national and global health problems. Ultimately, scientific institutions or professional organizations do not provide support for evidence-based decisions and policymaking. The science, technology, and innovation system are underdeveloped with an evident lack of effective and efficient operational tools to support and implement national science, technology, and innovation policies if present [2,3]. Additionally, the fast evolvement of knowledge, false information, and politicization expenses will further hamper trust in science and research outcomes globally and locally in the future. Scientific culture is weak with no exchange between the scientific community. Society and public trust in sciences as a means for a career do not exceed $30 \%$. No recognition of the positive impact of research in knowledge acquisition, addressing the root cause, and use in decision making and policies set at the national level. This could be attributed to lack of communication and misunderstanding of scientific research and new technology importance $[4,5]$.

Third key area is the use of scientific knowledge in national policy and decision making, international cooperation and development. Libya State did not comply to the recommendation on science and scientific researchers. Libya's shortcomings are attributed to decision makers, management and stakeholders in the research sector. as no strategic goals or sound results are found.

Fourth key area is promotion of science as a common good, and treating public funding of research and development as a form of public investment, that serve public interest and data sharing. Funding for research projects is not sufficient and only provided by the public sector. Decision-makers do not consider funding of (R\&D) as a form of indispensable public investment that should be held constantly before public opinion

Despite Libya being a country with the greatest R\&D intensity and highest in Gross domestic expenditure on research and development (GERD) as a percentage of GDP (GERD/GDP) ratio (2014), Libya contribution and production is either not reported due to ignorance or very low as compared to Arabic Countries [4]. The absence of vision and strategy is evidenced by a very low number of researchers and a very high number of technical staff per million habitants as compared to other Arabic countries [4]. In addition, the technicians are not very skilled and are not appropriately educated/ trained. Research is undermined in Libyan universities with very low investment This had negative regard to attract scientific researchers and maintain scientific progress and pool. No strategy to build bridges between universities and industry, and no prioritization for problem-solving research. No identification of (R\&D) priorities according to the strategic contribution to international knowledge production, diversifying Libya's income and technological capabilities through investment in such areas as solar energy and organic agriculture.

The Libyan government, Ministry of Education and Scientific Research, the Authority of Natural Science Research and Technology, and research centers are not facilitating sharing of data and educational resources helping in establishing partnerships with developed countries to build up scientific knowledge, prevent brain drain while protecting intellectual property rights and preventing biopiracy, illicit trafficking of tissues, samples, genetic resources and geneticrelated materials, and the confidentiality of personal data.

In reference to Fifth UNESCO recommendation to allow for inclusive and non-discriminatory work conditions with equal opportunities for the initial education and training and equitable conditions of work, Libya did not allow for participation of the concerned peoples and agreement on the benefits of the research and access to the results is not considered in the research agreement and terms for collaboration. There is no provision of material assistance, moral support, and public 
recognition.

Despite being prohibited by law, there is lack of equitable conditions of work, recruitment, and promotion, appraisal, training, and pay without discrimination in real work conditions $[4,5]$. In Libya about half of the students are women. there is almost missed data or a percentage shares in the low twenties, with no recognized contribution in Science, Technology, Engineering, and Mathematics (STEM) [6-8].

Sixth key area is subject of scientific conduction in a responsible manner respecting the human right and sharing scientific advancement and its benefits.

Libya does not adopt written provisions of researchers' rights in respect of their contributions to any discovery, invention, or improvement in technical know-how or commercialization, and do not protect intellectual property [4-6]. Libya Lack policies for the protection and preservation of research objects.

The production and spread of knowledge are dependent on national systems of research and innovation resulted from the organization between science, research, teaching institutions, industry, business, and government. We are so lagging as, in Libya, we have a serious problem with documentation, and data analysis. This led to ignorance of actual and current status, absence of statistics from Libya in regional and international reports, and injustice towards few achievements or no celebration of small wins $[4,8-10]$.

Libya lack good practices and well-defined appraisal systems transparent, and tier-based performance evaluation.

\section{Libyan researchers challenges}

Researchers undermined their rights and responsibility for free expression and constructive contribution to the science, culture, education, and innovation in Libya. Libyan researchers do not have an association to protect and promote their individual and collective interests and to ensure that fair satisfactory working conditions are available to researchers in all settings in which scientific research and development are conducted. Recently, Libya does not appear in the global innovation index, or showed low global innovation index and innovation efficiency ratio, in 2016 [11].

In reference to the seventh key recommendation for balancing the freedoms, rights, public accountability and responsibilities of researchers. Scientific researchers are excluded from participation in method placing or growing country-wide technological know-how, generation, and innovation policy. They have relative autonomy in deciding on subjects, in step with availability and allocated assets as there are only a few distinct outgoing projects through institutions, research centers, and it's frequently exclusive!

Research is performed randomly. Researchers aren't subjected to public responsibility of their research; however, they do now no longer experience running subjects because of a couple of constraints with the lack of budget, availability of wanted gadget and generation for studies tasks. This restricts the liberty and creativity of researchers and badly affected scientific progress. Researchers do now no longer have equitable get admission to scientific literature and couldn't goal favored journals in conjunction with limitations to publishing and sharing.

Scientific mobility of researchers among public sector, non-public sector, and higher education institute isn't always ensured. Protection of researchers and protection requirements isn't always absolutely met. No equitable social protection preparations suitable to their age, gender, family, their health, and nature of the work

Decision makers do not guard individual researchers' intellectual property rights and do not protect them from unjustified retribution. Since 2011, it isn't always approved to sign in a patent in Libya!.

Libyan researchers lack the commitment to the advancement of science and social and ecological responsibilities. As there is no obligation, most are ignoring the importance of being humanely, scientifically, socially, or ecologically responsible. They are not aware of the need to manage resources efficiently and sustainably. They do not express themselves freely and openly on the ethical, human and scientific value of certain projects, and in those instances undermine human dignity and human rights. An example the current unacceptable management of cancer patients, due to lack of drugs or late diagnostics or therapeutic interventions.

The eighth key recommendation is concerned with scientific integrity, ethical codes of conduct for science and research and their technical applications. There aren't any measures for the ethical support and encouragement of high-quality researchers to make a great profession with reasonable degree of security. Stakeholders do not promote access to research results engagement in sharing of scientific data with policymakers, and disclosure of each perceived and real conflicts of interest. Younger researchers lack possibilities to do sizeable studies in step with their abilities. Researchers have sporadic access to worldwide databases and journals, libraries, and information. Libya no longer provides attendance at meetings, conferences. Ethical committees are not implicated in clinical research. Currently, Libya has weak human and institutional capacities with a lack of science diplomacy.

The ninth key recommendation emphasis on the vital importance of human capital for a sound and responsible science system, and solicit member States to develop policies with respect to the training, employment, career prospects, and work conditions of scientific researchers. Libyan researchers are not provided with opportunities for education and training. No strengthening of sciences, technology, engineering, mathematics (STEM), art, and design education in schools and other informal education. In addition, there is no insistence on integrity, personal capacities such as reasoning, leadership, communication skills, teamwork, analytical mentality and intellectual maturity, qualities and respect for ethical principles during enrollment. Libya lacks contributions to publications, patents, management, teaching, outreach, supervision, collaboration, ethics compliance, and science communications, 
by combining appropriate metrics with independent expert assessment (peer review) of the individual's outputs.

\section{Prospective}

In reference to the Tenth UNESCO recommendation; concerning creating an enabling environment for a sound science system by facilitating satisfactory work conditions, moral support, and public recognition of successful performance of scientific researchers, and promoting publishing and sharing data and results that meet adequate quality standards; and by monitoring the implementation and impact of such efforts. Several steps have been taken for improvements, yet not sufficient. National Strategy SETI on 2014 determined long-term targets, to raise GERD to $2.5 \%$ of GDP by 2040 and to establish centers of excellence, smart cities, and special economic zones. The new strategy is being set again without the involvement of stakeholders! and without informing, lobbying awareness campaign, or the provision of current essential needs of research centers and researchers improvements, knowledge economy, a coherent agenda, and sustainable funding.

Improvements could be made as a decree was issued for the establishment of the Libyan Observatory for Science, Engineering, Technology and Innovation (SETI). However, it's not supported to do its job. Currently, we lack a Libyan landscape with complete ignorance of science, engineering, technology, and Innovation.

Women empowerment office in Ministry of higher education announced at Women celebration day/2021 issuing an annual Award of Women in Science. The theme was to promote Research. Honoring ceremony was held and the Women and Research award was given. This is a great step!.

Researchers should be compensated financially. New legislation was issued recently to promote salaries of researchers which even implemented yet, it's still very little as compared to others [12] to attract high caliber researchers.

Consultations were made with the Planning Department in the ministry of education and scientific research, Innovation department in the authority of Natural Science Research and Technology, Follow-up office in the authority of Natural Science Research and Technology, Office of women Empowerment in Ministry of Education, Research Funding Department in the authority of Natural Science Research and Technology, and research. An assessment of current status, supportive measures, and obstacles for scientific research and Science engineering technology and innovation (SETI) is conducted, Table-1.

The year 2021 is the time for Arabic Countries to provide their national report on UNESCO recommendations on science and research. It emphasizes on the free circulation of scientific data, and the need to provide scientists with adequate financial and institutional support. Libya have serious shortcomings in statistics, documentation, diffusion of information, etc, and did not invest in higher education and training to build a critical mass of experts to prevent brain drain to ensure achievements of SDGs. This represents a hurdle to submitting its a first national report on UNESCO recommendation.

Libya State needs to recognize the essential role of stakeholders and provide inclusive culture, that value and admit the science, technology, innovation and research importance to recognize the current status and to set strategic goals and for economic development.

A value chain comprising dynamic forces of academic, economic, industry, business and Politicians could realize the desired outcomes of SDGs and start a strategic plan in collaboration with all national and international stakeholders.

\section{Conclusion and recommendation}

The results showed clearly that research in Libya needs a governing body to conduct objective derived research that advances science, technology, innovation, and grow economy by uniting researchers, postgraduate students, and faculty members, industry from different disciplines such as in A*STAR and Kaust $[12,13]$.

This governance could be achieved through the inauguration of the Ministry of Social and scientific research with direct connection with the highest authority, governments, industry and economists for the adoption of evidence-based decisionmaking policy.

Availability of research advocate near decision-making stakeholders, mobilization of honest brokers, awareness campaigns for research importance and utility is mandatory in Libya.

In the health sector founding national Institute of Health (NIH) could guide stakeholders and the ministry of Health in a future health challenge as evidenced post Covid-19.

Libya needs to adopt legislation for the promotion of Research funding through taxes reduction on public and private sectors, and for allocation of a percentage of GDP for research funding in constitution comparable to developed countries for an immediate injection of a significant sum of money to kickstart Gold standard research in Libya [14].

Libya should assess the current situation and provide the essential updated infra-structure, recruit talents and promote national and international cooperation to ensure wise and efficient use of resources and robust research conduction and high-quality publication [3,15] and should participate actively in improving STEM in Africa [16].

To do that, Libya needs to apply and implement urgently operational tools [2], document data, use information system and analysis to create knowledge about science and research status, activate the SETI Observatory, and ensure that research centers are held accountable for expenses as compared to results (cost-effective studies).

Libya did not progress as required by recommendation of Science and Scientific Researchers [17]. Research should focus on developing education, good health, social and mental status, 
Table 1: Supportive measures, Challenges and obstacles for Science, Researchers and Science engineering technology and innovation (SETI).

\begin{tabular}{|c|c|}
\hline Topic & $\begin{array}{c}\text { Supportive measures } \\
\text { System. }\end{array}$ \\
\hline $\begin{array}{c}\text { Inclusive no discrimination (STI) } \\
\text { STI system and national and } \\
\text { international/ objectives }\end{array}$ & $\begin{array}{c}\text { Law ensure Non-Discrimination and Diversity } \\
\text { However, discrimination is being practices } \\
\text { indirectly }\end{array}$ \\
\hline STI and Society & $\begin{array}{c}\text { Law prohibited gender inequality, but there is no } \\
\text { supportive measures. }\end{array}$ \\
\hline Research informing Policy & No supportive measures \\
\hline Science is a Common Good & Despite supportive says, not appreciated in reality \\
\hline Human Rights Standards & Assured legally, Not practiced with equity \\
\hline Scientific Freedom and Scientific \\
Responsibility
\end{tabular}

Research Integrity, Research Ethics, and Ethics of STI

Human Capital for Research

No supportive measures

Enabling Environment for Science and Research
Supportive measures are selective
Challenges and obstacles

No reliable nor comprehensive data on Conditions of Scientific Researchers. No data Base. Difficulty of data gathering and lack of reports on discrimination elimination.

\section{No Real Targeting of 2030 of Agenda}

No research advocate to inform Public Policy and decision-making, It is not contribute to Science Diplomacy. And do not counteract Brain Drain. It does not helps achieve SDGs. lack of society Knowledge, Lack of applications of S\&T and Scientific Culture No Uses of S\&T Knowledge for Decision-Making and Policy. No prioritization of problem solving research. Lack of openness

Selective deprivation of high internationally recognized researchers. No Acknowledgment of importance of providing freedom

A lot. As many workers are not qualified as researchers.

No Careers development and mobility. No Learning and no availability of materials and infra-structure to continue their researches. International travel very limited and Monopolized.

No social Security for independent creative researchers. Many deprived from promotion or basic salary. No appraisal.

No Infrastructure and S\&T services

Public funding is mainly for salary of no real active researchers, and conduction rather than for research projects and development!! Work Conditions not optimal. No support of publication process.

Link: https://bit.ly/3EQuz2G

reducing dependency on oil, and diversifying energy and income resources, and establishment of new infrastructure for science, technical and vocational education, and achievements of SDGs.

\section{Acknowledgment}

Prof. Reida El-Oakly for his advice, Dr. Adel El-Tajoury and Dr. Hakim Glia for their comments.

\section{References}

1. Focused implementation: the 10 key areas of the UNESCO Recommendation on the Status of Scientific Researchers (2017). Link: https://bit.ly/3HwwXx6

2. National strategy for Science, Technology and innovation, 2014. Link: https://bit.ly/3foUpql

3. Nasef A (2020) Challenges and opportunities of medical research in Libya Arch Community Med Public Health 6: 28-30. Link: https://bit.ly/34gNyqy

4. UNESCO science report: towards 2030; 2015. Link: https://bit.ly/3sSkaB3

5. Cross R (2021) Will public trust in science survive the pandemic? Ryan Cross. Global Health 99. Link: https://bit.ly/3sTW3IA

6. Islam SI (2017) Arab Women in Science, Technology, Engineering and Mathematics Fields: The Way Forward. World Journal of Education 7: 12-20.
7. Huyer S (2020) 3 . Is the gender gap narrowing in science and engineering? Link: https://bit.ly/3sSXLUo

8. Link: https://bit.ly/3JMIJ8K

9. Jerome B (2005) Towards knowledge societies: UNESCO world report 237. Link: https://bit.ly/3mMObAj

10. Towards Knowledge Societies. UNESCO 2005. Link: https://bit.ly/3zjhei9

11. The Global Innovation Index 2020. Who Will Finance Innovation?. Link: https://bit.ly/3JFvdno

12. Link: https://www.a-star.edu.sg/

13. KAUST shall be a beacon for peace, hope and reconciliation, and shall serve the people of the Kingdom and the world. Link: https://bit.ly/34lzkot

14. El Oakley RM (2013) Underfunding Health Research: Failure of Diplomacy or Lack of Political-Will? Int J Health Res Innovat 1: 19-27. Link: https://bit.ly/3mRegMP

15. Nasef A, Taguri AE (2020) Boosting Research for Health in Libya and Developing Countries. Research Incubtors. Arch Community Med Public Health 6: 042-044. Link: https://bit.ly/3zivYhk

16. Nasef A, Taguri AE (2020) Health research production in developping countries/africa. Ann Bone Marrow Res 5: 006-0010. Link: https://bit. 